UDK 528.94:551.4

\title{
ESTIMATING EULER POLE PARAMETERS FOR EASTERN CANADA USING GPS VELOCITIES
}

\author{
Mohammad Ali GOUDARZI ${ }^{1}$, Marc COCARD ${ }^{2}$, Rock SANTERRE ${ }^{3}$ \\ Department of Geomatics Sciences, Louis-Jacques-Casault Building, Laval University, \\ Quebec (QC), G1V 0A6, Canada \\ E-mails: ${ }^{1}$ mohammad-ali.goudarzi.1@ulaval.ca (corresponding author); \\ ${ }^{2}$ marc.cocard@scg.ulaval.ca; ${ }^{3}$ rock.santerre@scg.ulaval.ca \\ Received 12 June 2015; accepted 03 November 2015
}

\begin{abstract}
Eastern Canada is characterized by many intraplate earthquakes mostly concentrated along the Saint Lawrence River and Ottawa River valleys. After the rigid plate rotation of North America, the glacial isostatic adjustment (GIA) is by far the largest source of geophysical signal in eastern Canada. We estimate a set of Euler pole parameters for this area using a velocity field of 19 continuously operating GPS stations out of 112, and show that they are different from the overall rotation of the North American plate. This difference potentially reflects local stresses in this seismic region, and the difference in intraplate velocities between the two flanks of the Saint Lawrence River valley accumulate stress along the river.
\end{abstract}

Keywords: Euler pole estimation, GPS, eastern Canada, glacial isostatic adjustment.

\section{Introduction}

Eastern North America is subject to two major geophysical processes: glacial isostatic adjustment (GIA) and intraplate tectonic activities. The GIA is the response of the elastic earth to unloading the ice sheets since the last glacial maximum (LGM) about $20 \mathrm{kYBP}$ and causes deformations in the form of radial uplift or subsidence (van der Wal et al. 2009). Before the LGM, most of the Canadian landmass and part of northern United States were covered by the Laurentide ice sheet (LIS) with the thickness of more than $3 \mathrm{~km}$ extended over several thousands of kilometers (Andrews 1991). The consequence was subsidence of earth's crust at the ice domes and creation of forebulges or uplift at peripherals. Since the LGM, this process has become inverted by the viscous flow of the mantle from peripherals to the centers of the glaciated areas causing radial deformations. This has been measured to the current maximum radial uplift of $\sim 14 \mathrm{~mm} / \mathrm{yr}$ in the east of Hudson Bay (Goudarzi et al. 2015a).

Intraplate tectonic is another geophysical phenomenon within the boundaries of the North American plate. The GIA produces horizontal velocities that are typically directed radially outward from regions of highest uplift, but have smaller rates than vertical velocities (Henton et al. 2006). Therefore, it has a direct effect on the estimated velocities of stations in areas where this phenomenon occurs. The GIA-related crustal deformation in central and eastern North America is very well documented and interested readers can refer to Andrews (1991), Lambert et al. (2001), Park et al. (2002), Sella et al. (2004), Braun et al. (2008), van der Wal et al. (2009), and Lavoie et al. (2012), among others.

According to Euler's rotation theorem, the movement of a rigid body on the surface of a sphere can be described as a rotation around an axis that passes through the center of the sphere. The theorem states that the displacement of a tectonic plate relative to other plates takes place as a rotation about the Euler pole of relative rotation between the plates (Lowrie 2007). Using this theorem, it is possible to find a location (i.e., pole of rotation) to fix a tectonic plate in space so that intraplate motions can be analyzed. The Euler pole can be located by different methods such as transform fault azimuths, earthquake slip vectors, and spreading rates at mid-ocean ridges (Argus, Gordon 1991; Chase 1972; DeMets et al. 1990; Minster, Jordan 1978). However, increasing number of continuous GPS (CGPS) stations and their observation period along with improving 
accuracies, make them an alternative method for estimating the Euler pole parameters (Altamimi et al. 2012, 2007, 2002; Argus, Heflin 1995; Kreemer et al. 2006; Sella et al. 2002). Therefore, we estimate the Euler pole parameters for eastern Canada using observations of the CGPS stations located in the stable interior part of the North American plate. This area is characterized by substantial seismicity and earthquake hazards as well as the GIA that makes it to behave as a non-rigid body. This research is intended to answer the question about the rigidity of this region with respect to the North American plate. Results of this research would be useful for strain analysis of eastern Canada, especially in the western Quebec and the Saint Lawrence River valley seismic zones.

This work has the following structure. First, the mathematical form of the Euler's theorem, which is used for estimation of the rotation parameters, is presented in Section 1. Then, the seismic background of eastern Canada is briefly reviewed in Section 2 with emphasis on the GIA. The current GIA in this region has a strong impact on the CGPS horizontal and vertical velocities and makes the station selection a very important issue. Therefore, the criteria for selecting proper CGPS stations, especially with respect to the GIA and seismicity of the area are introduced and discussed in Section 3 along with the CGPS data processing. This is followed by estimating and testing the Euler pole parameters in Section 4. Finally, the estimated parameters are compared with those officially published for the North American plate, and residual velocities are discussed in Section 5. The conclusion is presented in the last section.

\section{The Euler's theorem}

The Euler's theorem can mathematically be formulated as:

$$
\mathbf{v}_{i}^{P}=\boldsymbol{\Omega}^{P} \times \mathbf{x}_{i}^{P},
$$

where $\mathbf{v}_{i}^{P}$ and $\mathbf{x}_{i}^{P}$ are the velocity and the position vectors of station $i$ and $\boldsymbol{\Omega}^{P}$ is the angular velocity or the Euler vector of the plate $P$, all in an earth-centered earth-fixed Cartesian coordinate system (ECEF CCS). Magnitude of the Euler vector $\left(\Omega^{P}=\left|\Omega^{P}\right|\right)$ is the rotation rate of the plate $P$ that is usually expressed in degrees per million years ( $\left.{ }^{\circ} / \mathrm{Myr}\right)$. The direction of the Euler vector $\left(\hat{\boldsymbol{\Omega}}^{P}=\boldsymbol{\Omega}^{P} / \Omega^{P}\right)$, also called the "Euler pole", is often expressed in spherical latitude and longitude in degrees. In this rotation model, the plate $P$ is basically constrained to move rigidly on the spherical surface of the earth without a radial motion. Using (1), it is possible to calculate Euler pole parameters by inverting a set of observed velocity and position vectors of some measuring stations located on the same rigid block.

\section{Seismicity of the study region}

Although far from tectonic plate's boundaries, eastern Canada located within the stable part of the North American plate is characterized by many intraplate earthquakes and most of the region is substantially seismic. According to NRCan (2013), on average, 450 earthquakes occur every year in eastern Canada with 4 events exceeding magnitude 4 , and every decade includes 3 events greater than magnitude 5. Although earthquakes can occur everywhere in eastern Canada, the earthquake catalogue of seismicity in this region (Fig. 1) clearly shows five distinct clusters of seismic activity in (a) Baffin Bay to the eastern north continental margin, (b) a band from northwest of Hudson Bay to north of Quebec, (c) along the Saint Lawrence River valley (SLRV) and Ottawa valley, (d) the northern Appalachians region including most of New Brunswick and extending into New England down to Boston, and (e) the Laurentian slope comprising southeastern coast of Canada and including the Grand Banks of Newfoundland (Adams, Basham 1991, 1989a, 1989b; NRCan 2015, 2013; Mazzotti, Adams 2005).

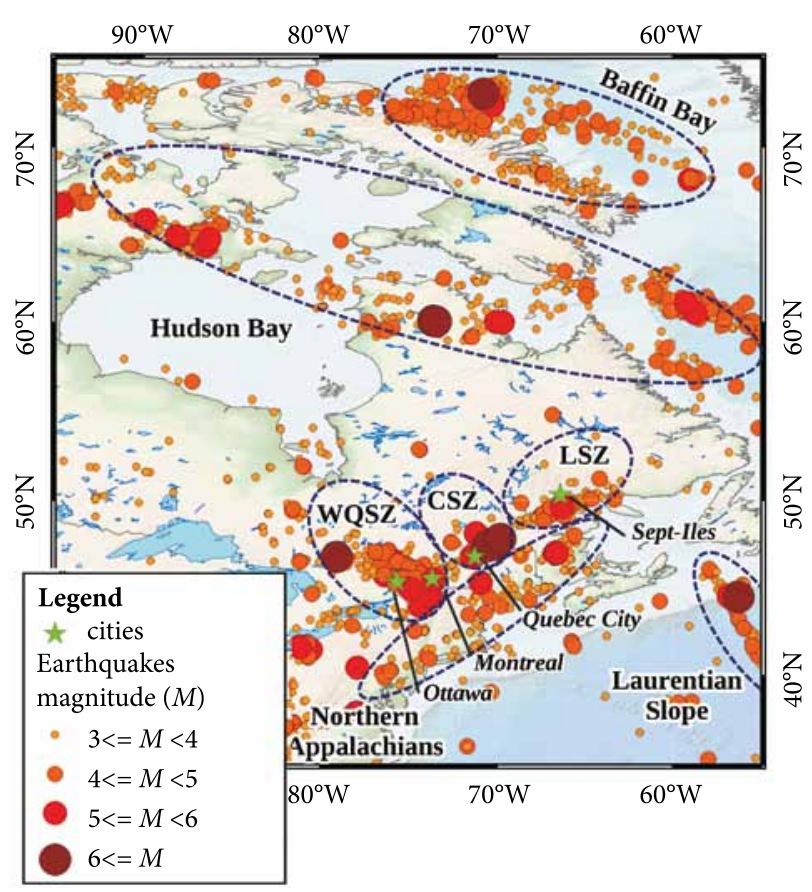

Fig. 1. Instrumental earthquakes with $M \geq 3$ recorded from 1945 until mid-2014 and historical earthquakes estimated since 1663 in eastern Canada (data source: Earthquake Canada and the Advanced National Seismic System of the United States). The clusters of seismic activities are delineated as well as the seismic zones along the Saint Lawrence River valley 
Seismicity varies significantly within these zones. In 1982, a series of earthquakes occurred in the northern Appalachians seismic zone with $M=5.7$ for the largest event. The large earthquake $(M=7.2)$ of 1929 near the Grand Banks in the Laurentian slope seismic zone produced a large tsunami. Along the SLRV and the Ottawa valley, earthquakes are mainly concentrated in three distinct clusters of activity: western $\mathrm{Qu}$ ebec seismic zone (WQSZ) along the Ottawa River from Montreal to Temiscaming as well as Laurentians and eastern Ontario, Charlevoix seismic zone (CSZ) located about $100 \mathrm{~km}$ downstream from Quebec City, and Lower Saint Lawrence seismic zone (LSZ) located in the estuary of the SLRV about $400 \mathrm{~km}$ far from Quebec City (Adams, Basham 1991; NRCan 2013). At least 4 earthquakes with $M \geq 5$ have been recorded in the WQSZ in $1732(M=5.8), 1935(M=6.2)$, $1944(M=5.6)$, and $1990(M=5)$. The CSZ is locus of the strongest earthquakes among other seismic zones. This zone has been subject to at least five large $(M \geq 6)$ events in the past 350 years in $1663(M=7)$, $1791(M=6), 1860(M=6), 1870(M=6.5)$, and 1925 $(M=6.2)$. The LSZ has the lowest rate of seismic activity and only two earthquakes of $M \geq 5$ have been occurred in $1944(M=5.1)$ and $1999(M=5.1)$ in this area.

Large earthquakes in eastern Canada have been deadly. The $M=6.5$ earthquake of 1870 had two casualties in the Les Éboulements area (Lamontagne 2008). 27 people were completely drowned on the south coast of Newfoundland due to the consequent tsunami of the $M=7.2$ Grand Banks earthquake in 1929 (Adams, Basham 1989a). This seismic background shows the probability of occurring earthquakes all along the SLRV and Ottawa valley. Whether damaging or not, recurrence of such earthquakes is an important issue for the seismic hazard especially in the urban centers of Quebec City, Montreal, Ottawa, Gatineau, and Cornwall.

\section{CGPS network and observations}

The CGPS stations that provide the basis of this research are those presented and discussed in Goudarzi et al. (2015a, 2015b). They have processed observations of 112 CGPS stations in eastern Canada with the scientific Bernese GNSS Software v5.0 (Dach et al. 2007) and estimated loosely constrained daily positions of the stations in ITRF 2008 using an ionospheric-free, double-difference, ambiguity-fixed phase resolution with precise satellite orbits and earth's rotation parameters from the International GNSS Service (IGS) (Dow et al. 2009). The advantage of the loosely constrained solution is that none of the station coordinates or velocities have a priori constraints that distort the internal consistency of the solution (Kierulf et al. 2014). The output of the CGPS data processing is the position time series of stations in a local geodetic reference frame (north, east, and up directions). They estimated linear velocities of stations as well as all possible jumps and annual/semi-annual signals in the position time series with the weighted least-squares regression method after removing outliers using the GITSA software (Goudarzi et al. 2013b). Using position time series of stations as input data has the advantage of isolating and controlling the non-linear movement and all other types of discontinuities (e.g., coseismic shift or antenna height change) and leads to a consistent secular robust solution. The result of the data processing is a velocity field that shows the wellknown counterclockwise rotation of the North American plate in a no-net-rotation frame with respect to ITRF 2008 (Goudarzi et al. 2015a).

Selecting proper CGPS stations is a very important issue in this context. As this region is affected by land uplift and subsidence related to the GIA, many stations have a strong correlation to this process and are biased if analyzed for the Euler pole estimation. Therefore, some geodetic and geophysical aspects should be taken into account, such as: distance to plate boundaries and intraplate deformation zones, spatial geometry of stations, and reliability of their estimated velocities. Following the recommendations given by Altamimi et al. (2012), we selected a subset of the processed CGPS stations from Goudarzi et al. (2015a) based on the following conditions: (a) having reasonably long observation period, (b) being located on the stable interior part of the North American plate, (c) having stable monument, and (d) passing appropriate statistical tests explained in Section 4.

The first condition prevents biasing velocities by seasonal variations in short position time series (Blewitt, Lavallée 2002). Therefore, we conservatively considered stations with more than three years of observations, although they recommend that 2.5 years can be adopted as a standard minimum data span for velocity solutions intended for tectonic interpretation or reference frame realization. This choice has also been made by other researchers, e.g., Kierulf et al. $(2014,2013)$. In fact, 108 stations out of 112 satisfy this condition. The second condition is necessary to satisfy the theory of the rigid plate motion. In their global 
solution, Altamimi et al. (2012) select stations which are located more than $100 \mathrm{~km}$ far from Bird's plate boundaries (Bird 2003), outside of the deformation zones according to criteria of Argus and Gordon (1996) and the strain model of Kreemer et al. (2014), and also far from GIA-affected regions. Criteria of Argus and Gordon state that for assigning a station to a tectonic plate, it should be far from the active faults, large earthquakes, and tectonic topography that mark plate boundaries. While our regional velocity field in eastern Canada is already far enough from plate boundaries and high strain rate fields, we verified the occurrence of large earthquakes near the CGPS stations using earthquake catalogue of Canada (NRCan 2015). Spatial analysis with the buffer distance of $100 \mathrm{~km}$ (Sella et al. 2007) around epicenters of earthquakes with $M \geq 4$ occurred within the time span of the data (from January 2000 to June 2014) showed that 25 stations are located within the buffer zone and might be affected by earthquakes. Therefore, 87 of the CGPS stations satisfy this condition. Moreover, the region is highly affected by the GIA (Introduction), which is a non-stationary and non-rotational geophysical signal. The effect of the GIA on the horizontal velocities can be corrected using a GIA model before estimating the Euler pole parameters. However, Altamimi et al. (2012) show that the GIA correction using the model of Schotman and Vermeersen (2005) or ICE-5G VM2/VM4 from Peltier (2004) significantly degrades the velocity fit in both horizontal directions over the North American plate. This is primarily because the GIA models are overestimated in North America compared to geodetic data (Argus, Peltier 2010). Therefore, we decided to estimate the Euler pole parameters directly using stations not affected by the GIA. This choice is independent of any GIA model and does not consider the GIA horizontal velocity predictions. The criterion to identify GIA-affected stations is to have modelled vertical velocity of larger than $0.75 \mathrm{~mm} / \mathrm{yr}$ (Altamimi et al. 2012). Applying this criterion on the vertical velocity model presented in Goudarzi et al. (2015a) identified 26 stations satisfying this condition. The third condition guaranties that the GPS velocities present the real tectonic movement of earth's crust rather than local instability of the stations' monuments. For the stability of the stations, we rely on the results of Goudarzi et al. (2015b). They have identified 7 stations with high random-walk noise amplitude attributed to station instability (Langbein, Johnson 1997). Therefore, 105 stations satisfy the third condition. In addition to the station analysis, direction of the horizontal velocity at station $\mathrm{MCHN}$ is not in agreement with the overall rotation of the North American plate and vertical velocities at stations GODR and LOZ1 have very different vertical velocities with larger sigma values compared to the nearby stations (Goudarzi et al. 2015a). Thus, these three last stations are also excluded.

Figure 2 displays the spatial distribution of all the CGPS stations in six different classes with different colors and symbols. Our final selection that satisfies all the conditions includes 20 stations shown with green triangles in this figure. They are spatially distributed

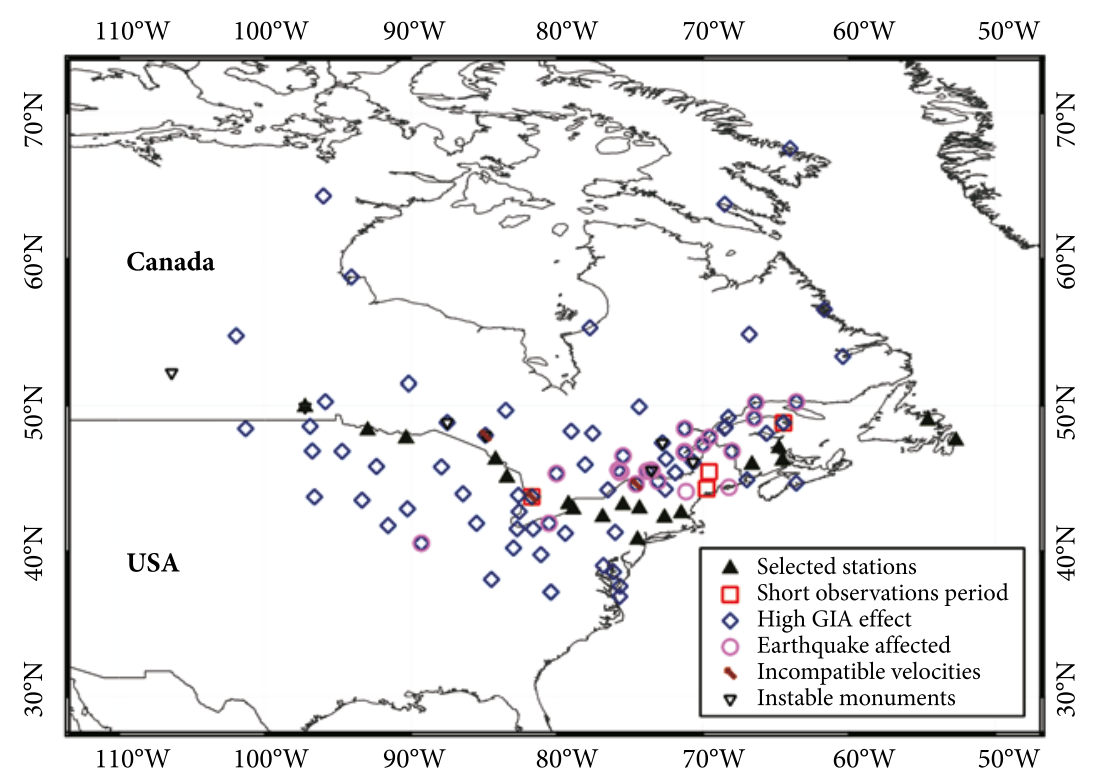

Fig. 2. Spatial distribution of the CGPS stations used in this study. Green solid triangles show the final selection. Other stations are excluded from the estimation process because they are affected by different phenomena explained in the text and therefore do not present the real tectonic rotation of the study region 
in the east-west direction and have a good geometrical coverage over the survey network. The figure shows that some stations have been excluded due to more than one reason. Southern stations with high effect of the GIA (marked with blue rhombs on the map) are related to subsidence of peripheral forebulges after the LGM. Estimated velocities of the selected stations and their one-sigma uncertainties are listed in Table 1. In this list, 6 stations belong to the IGS network with 2 stations designated as reference frame stations. This ensures consistency and stability of the selected stations.

Although the table includes the vertical velocities, they will not be used for estimating parameters. As Goudarzi et al. (2013a) discuss, vertical velocities do not contribute to the estimation of the Euler pole parameters, but affect the a-posteriori sigma value and artificially enlarge the elements of the covariance matrix of the estimated parameters. Therefore, the vertical components of velocity vectors should be set to zero before they are transformed from a local geodetic (LG) to an ECEF CCS.

\section{Estimating Euler pole parameters}

Applying different constraints in Section 3, the large number of CGPS stations in eastern Canada was reduced to 20, which are found along the so-called hinge line or axis-of-tilting of the land uplift/subsidence process and are considered to show the true plate motion allowing the estimation of Euler pole for the study region. We iteratively estimated the Euler pole parameters using Equation (1) with our EPC software (Goudarzi et al. 2013a). All velocities were weighted with their full covariance matrices obtained from the CGPS data processing. This preserves the correlation between velocity components of each station. We performed three statistical tests, namely, $\chi^{2}$-test of goodness of fit, Pearson's correlation coefficient, and the

Table 1. The selected CGPS stations in eastern Canada for estimating the Euler's pole of rotation

$\left(^{*}\right.$ : IGS station, rf: IGS reference frame station, d: decommissioned station

Monuments: DB: Deep-drilled braced, CP: Concrete Pillar/Pier, AP: Aluminum Pillar, SP: Steel Pillar, FB: Fixed to building, B: Bedrock)

\begin{tabular}{|c|c|c|c|c|c|c|c|c|}
\hline \multirow{2}{*}{ No. } & \multirow[t]{2}{*}{ Station } & \multirow[t]{2}{*}{ Long. $\left({ }^{\circ} \mathrm{W}\right)$} & \multirow[t]{2}{*}{ Lat. $\left({ }^{\circ} \mathrm{N}\right)$} & \multirow[t]{2}{*}{ Monu. } & \multirow[t]{2}{*}{ Len. (yr) } & \multicolumn{3}{|c|}{$\begin{array}{l}\text { Estimated velocities and uncertainties } \\
\qquad(\mathrm{mm} / \mathrm{yr})\end{array}$} \\
\hline & & & & & & North & East & Up \\
\hline 1 & BFNY & 78.890 & 42.878 & $\mathrm{FB}$ & 11.93 & $2.46 \pm 0.24$ & $-16.07 \pm 0.03$ & $-0.35 \pm 0.82$ \\
\hline 2 & $\mathrm{ESCU}^{*}$ & 64.799 & 47.073 & CP-B & 9.55 & $7.79 \pm 0.32$ & $-15.75 \pm 0.05$ & $-0.22 \pm 1.02$ \\
\hline 3 & $\mathrm{FRDN}^{*}$ & 66.660 & 45.934 & DB-B & 11.00 & $7.01 \pm 0.43$ & $-16.02 \pm 0.12$ & $0.05 \pm 1.15$ \\
\hline 4 & GDMA & 90.341 & 47.748 & $\mathrm{FB}$ & 12.12 & $-2.52 \pm 0.33$ & $-17.59 \pm 0.05$ & $0.29 \pm 1.02$ \\
\hline 5 & HAMP & 72.639 & 42.318 & FB & 11.86 & $3.91 \pm 0.26$ & $-13.87 \pm 0.04$ & $0.74 \pm 0.92$ \\
\hline 6 & MIAL & 83.428 & 45.063 & $\mathrm{FB}$ & 8.00 & $0.38 \pm 0.50$ & $-16.62 \pm 0.17$ & $-0.52 \pm 1.72$ \\
\hline 7 & MINB & 84.210 & 46.284 & $\mathrm{FB}$ & 6.65 & $-0.09 \pm 0.45$ & $-17.31 \pm 0.19$ & $0.99 \pm 2.08$ \\
\hline 8 & MNAS & 92.970 & 48.294 & $\mathrm{CP}$ & 3.84 & $-3.66 \pm 1.02$ & $-17.92 \pm 0.28$ & $-1.46 \pm 3.58$ \\
\hline 9 & NJMT & 74.483 & 40.796 & $\mathrm{FB}$ & 9.16 & $4.22 \pm 0.51$ & $-14.92 \pm 0.16$ & $-0.68 \pm 1.45$ \\
\hline 10 & NYFV & 74.353 & 42.939 & $\mathrm{FB}$ & 8.18 & $3.97 \pm 0.37$ & $-15.64 \pm 0.05$ & $0.44 \pm 1.16$ \\
\hline 11 & NYRM & 75.487 & 43.178 & FB & 8.19 & $3.41 \pm 0.29$ & $-15.80 \pm 0.05$ & $0.16 \pm 1.16$ \\
\hline 12 & NYWG & 76.876 & 42.351 & FB & 5.71 & $2.95 \pm 0.46$ & $-15.72 \pm 0.09$ & $-0.62 \pm 1.77$ \\
\hline 13 & PWEL & 79.220 & 43.237 & $\mathrm{AP}$ & 8.99 & $2.43 \pm 0.30$ & $-15.76 \pm 0.08$ & $-0.42 \pm 1.19$ \\
\hline 14 & $\mathrm{SHE}^{*}$ & 64.552 & 46.221 & SP-B & 7.38 & $7.78 \pm 0.54$ & $-15.89 \pm 0.15$ & $0.63 \pm 1.44$ \\
\hline 15 & $\mathrm{STJO}^{\star \mathrm{rf}}$ & 52.678 & 47.595 & CP-B & 14.49 & $13.13 \pm 0.48$ & $-15.25 \pm 0.14$ & $-0.88 \pm 1.46$ \\
\hline 16 & $\mathrm{UNB}^{\mathrm{d}}$ & 66.642 & 45.950 & $\mathrm{FB}$ & 5.07 & $7.20 \pm 0.69$ & $-16.23 \pm 0.12$ & $-0.34 \pm 1.94$ \\
\hline 17 & $\mathrm{UNBJ}^{*}$ & 66.642 & 45.950 & FB & 7.86 & $7.34 \pm 0.40$ & $-15.59 \pm 0.15$ & $0.04 \pm 1.50$ \\
\hline 18 & WES $2^{\star r f}$ & 71.493 & 42.613 & SP & 14.49 & $5.30 \pm 0.31$ & $-15.51 \pm 0.11$ & $0.23 \pm 1.05$ \\
\hline 19 & WINN & 97.260 & 49.901 & FB & 14.48 & $-5.23 \pm 0.52$ & $-17.04 \pm 0.09$ & $0.94 \pm 1.19$ \\
\hline 20 & YQX1 & 54.598 & 48.966 & $?$ & 6.18 & $9.92 \pm 0.61$ & $-15.33 \pm 0.12$ & $0.93 \pm 1.99$ \\
\hline
\end{tabular}


Pope's $\tau$-test (Pope 1976) at each iteration to ensure the statistical significance of the results. All these tests are already implemented in the EPC software. We especially tested residual velocities using the $\tau$-test at $95 \%$ confidence level. This test is well suited to find blunders in the input data set, and can be used to exclude stations with gross errors in their velocities. At each iteration, we only excluded one station with the maximum square root of standardized residuals for two reasons: (a) the existence of any blunder in the data set will affect the remaining observations, and (b) the rejection level of the test depends on the a-posteriori sigma value (Ghilani 2010). This test only rejects the STJO station (the most eastern station in Fig. 2). All the remaining stations pass the $\tau$-test and the other two tests as well. The estimated Euler pole parameters for eastern Canada with respect to ITRF 2008 (EC08) obtained from inversion of station velocities are listed in Table 2. The estimated sigma values are decreased by excluding the STJO station. The sigma is a product of the a-posteriori sigma and the cofactor matrix that contains information about geometry of the network. When this product is minimum, the geometry of the remained stations is optimum. Therefore, our final estimation is obtained after excluding the station that cannot pass the $\tau$-test.

The residual velocities are within a $\pm 1.5 \mathrm{~mm} / \mathrm{yr}$ interval, as illustrated in Fig. 3. This strongly supports the idea that the retained stations in the final inversion can be good representatives for determination of the Euler pole of eastern Canada.

\section{Discussion}

The station selection is crucially important in estimating Euler pole parameters where the GIA signal is present. It makes the interpretation of residual velocities difficult as they will include parts of the North American plate motion, which is not well estimated by the regional array, parts of the GIA signal but not all of that since some of it may be included in the rigid rotation estimation, and maybe parts of the seismic strain.

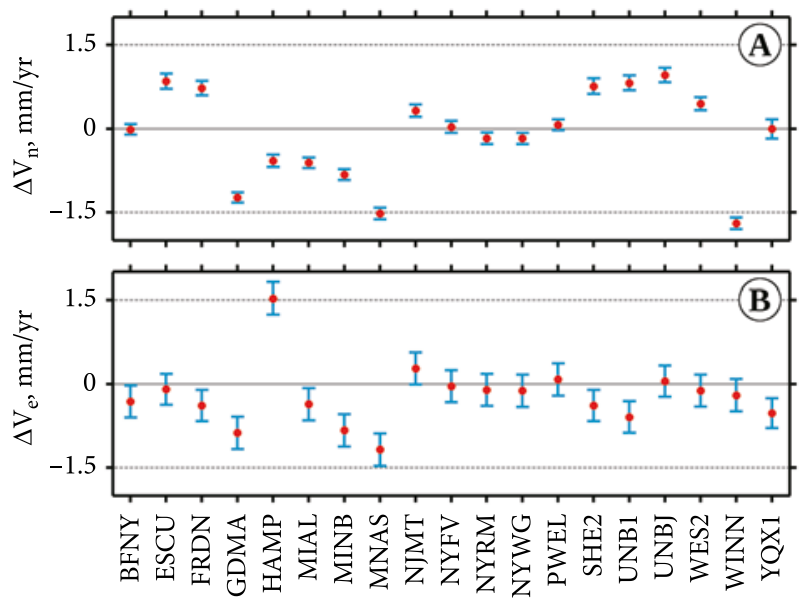

Fig. 3. (A) North and (B) east residual velocities for the final 19 stations used for the estimation of the absolute Euler pole of rotation for eastern Canada. In general, east residuals are smaller than north residuals despite their larger uncertainties. This explains the better accuracy in longitude of the estimated rotation pole shown in Table 2

In fact, the correct procedure would be to estimate the Euler pole parameters from stations far away from the area affected by the GIA.

The absolute Euler pole parameters for the entire North American plate have been already estimated by other researchers using different methods and data sets, and in different reference frames, e.g., Kreemer and Holt (2001), Sella et al. (2007), Argus et al. (2010), DeMets et al. (2010), and Altamimi et al. (2007, 2002). Here, we compare our estimation with the results obtained from the geodetic data sets constrained to the same reference frame for making the comparison meaningful. Table 2 includes also results of Altamimi et al. (2012) for North America (NOAM08). They have calculated an absolute tectonic plate motion model for 14 major tectonic plates using the ITRF 2008 velocity field of 206 selected stations and their full covariance matrix with 44 stations across the North American plate. They used a single inversion method, thus preserving the correlations among velocity parameters. The table shows while our primary results (before $\tau$-test) are not significantly different from the NOAM08, the final results are statistically different, indicating a different

Table 2. Estimated absolute Euler poles of rotation

(EC08: eastern Canada ITRF 2008, NOAM08: North American plate ITRF 2008 from Altamimi et al. (2012), NS: number of stations)

\begin{tabular}{|c|c|c|c|c|c|}
\hline \multicolumn{2}{|c|}{ Model } & NS & Lat. $\left({ }^{\circ}\right)$ & Long. $\left({ }^{\circ}\right)$ & Omega $\left({ }^{\circ} / \mathrm{Myr}\right)$ \\
\hline \multirow{2}{*}{ EC08 } & before $\tau$-test & 20 & $-9.879 \pm 1.912$ & $-86.038 \pm 0.577$ & $0.179 \pm 0.006$ \\
\cline { 2 - 7 } & after $\tau$-test & 19 & $-12.531 \pm 1.666$ & $-86.444 \pm 0.544$ & $0.173 \pm 0.005$ \\
\hline \multicolumn{2}{|c|}{ NOAM08 } & 44 & $-8.578 \pm 0.686$ & $-86.974 \pm 0.692$ & $0.186 \pm 0.002$ \\
\hline
\end{tabular}


Euler pole in latitude with a different rate of rotation for this area. The difference in latitude is larger compared to longitude, while the magnitudes of rotation are closer. This indicates that the area is not rotating rigidly with the North American plate and has its own movement within the plate, potentially reflecting local stresses in the seismically active region of eastern Canada. Other reasons for this difference could be the different number and the spatial distribution of stations: while the NOAM08 model includes 44 stations, the EC08 model is estimated using 19 stations. Furthermore, the NOAM08 stations are located on the center and eastern America and are far from the active areas to the west, while our stations only located on the eastern North America. Therefore, it can fit better to the velocity field in this area.

We calculated horizontal residual velocities of all stations using the EC08 model, illustrated in Fig. 4 by blue arrows. The figure also shows horizontal residual velocities calculated from estimation of Altamimi et al. (2012) by red arrows. The overall horizontal velocity of the North American plate is modelled and removed very well by applying either of models. Modelling the plate rigid body rotation might also remove some of the GIA components and makes a small bias to the horizontal residual velocities (Sella et al. 2007). The horizontal residual velocities, which are due to a nonrotational signal, indicate intraplate deformations. In general, both residual velocities are in agreement and clearly show a pattern of horizontal movement consistent with geophysical GIA models, e.g., ICE-5G
(Peltier 2004). Although scattered, they are radially outward at large distances from the center of the maximum uplift (east of Hudson Bay) to the peripheral bulges (north of the United States) and radially inward to the bottom of subsidence. This area is corresponding to the Labrador ice sheet. The area where the residual velocities have zero magnitude is very near or on the hinge line between uplift to the north and subsidence to the south. Most of our selected stations are located along this hinge line. Magnitude of the horizontal residual velocities is minimum under the ice dome centers, due primarily to unbending of the lithosphere and relaxation and flow of the asthenosphere (Sella et al. 2007). This residual velocity field is in agreement with other analysis of CGPS stations, e.g., Calais et al. (2006) and Sella et al. (2007), and the Canadian base network (CBN) by Henton et al. (2006). In addition, the horizontal residual velocities show motions directed outward from two other ice maxima to the northwest and the northeast of Hudson Bay, namely, Keewatin ice sheet and Foxe ice cap that appear to correspond with the possible late Wisconsinan configuration of late Quaternary ice masses over North America (Andrews 1991). However, our data are very sparse in the latter area (only two CGPS stations) that strongly limits the interpretation of the results. So, our horizontal residual velocity field confirms the multidomed model of the LIS with two main centers over Labrador and Keewatin ice sheets and one other smaller dome shown as the Foxe ice cap, among others postulated (e.g., Törnqvist, Hijma 2012).

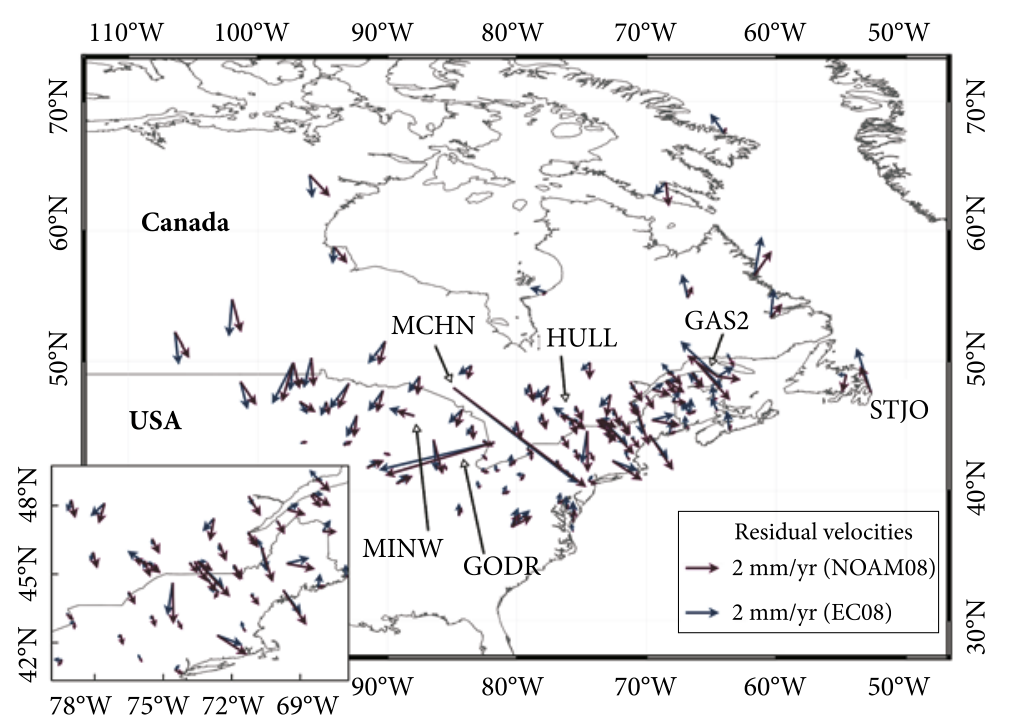

Fig. 4. Intraplate horizontal velocities calculated from Euler poles for the North American plate ITRF 2008 (NOAM08) and from eastern Canada ITRF 2008 (EC08) models illustrated by red and blue arrows, respectively. Although consistent to the first degree, the EC08 intraplate horizontal velocities are generally smaller over the Saint Lawrence River valley (see the inset). This shows the EC08 model can model the horizontal velocity field of this region better than the NOAM08 model. 
The direction of horizontal residual velocities at GAS2, GODR, HULL, MCHN, and MINW are not in agreement with the GIA-induced horizontal velocities, but they are presumably attributed to the combination of local station effects and intraplate tectonic signals. Very large residual velocities at GAS2, GODR and MCHN are attributed to their short time series $(2.77 \mathrm{yr}$ for GAS2 and $1.82 \mathrm{yr}$ for GODR) and instability of the stations (high random-walk amplitude) reported by Goudarzi et al. (2015b). The HULL station might be subject to non-tectonic local variations especially because its nearby stations, i.e., CAGS, GATI, and NRC1 show the expected outward motion. The reason for misbehavior of the MINW station is not clear.

Both residual velocities to the west and north of the SLRV have a larger magnitude than those of the opposite side implying a continuous shortening along the valley. Mazzotti et al. (2005) have measured the horizontal strain rate of this shortening equals to $1.7 \pm 1.0 \times 10^{-9} / \mathrm{yr}$ mostly in ESE-WNW direction. This shortening is also consistence with motion of the margins of the former LIS away from its center.

The calculated horizontal residual velocities for all the CGPS stations in both models are illustrated in Fig. 5. The figure shows most of them are still within $\pm 1.5 \mathrm{~mm} / \mathrm{yr}$ interval. In the north direction, the difference between residual velocities is lowest for western stations, and is increased systematically for eastern stations. This systematic increase, however, is not seen in the east direction. Instead, residual velocities estimated by the EC08 model are generally shifted towards west compared with the NOAM08 estimated velocities in this direction. The same result was obtained by sorting stations according to their latitudes: lowest difference between residual velocities for most southern stations compared with northern stations in the north direction, and shifting the residual velocities to the west in the EC08 model. The minimum difference between western and southern stations is mainly due to the aggregation of stations to the center of North Ameri$\mathrm{ca}$ in the NOAM08 model, while the shift in the east direction of the residual velocities is related to larger effect of the change in latitude on the east component of the estimated velocity (the magnitudes of the change in the estimated velocities due to change in the latitude of the Euler pole at the geometrical center of our GPS network are $0.03 \mathrm{~mm} / \mathrm{yr}$ and $0.52 \mathrm{~mm} / \mathrm{yr}$ in north and east components, respectively).

The velocities range between $0.05-2.81 \mathrm{~mm} / \mathrm{yr}$ in the EC08 and between $0.05-3.34 \mathrm{~mm} / \mathrm{yr}$ in the NOAM08 model. Overall, $64 \%$ of stations in the EC08 model and $71 \%$ of stations in the NOAM08 model have their velocities between $0.5 \mathrm{~mm} / \mathrm{yr}$ and $2.5 \mathrm{~mm} / \mathrm{yr}$. This is in agreement with several previous publications
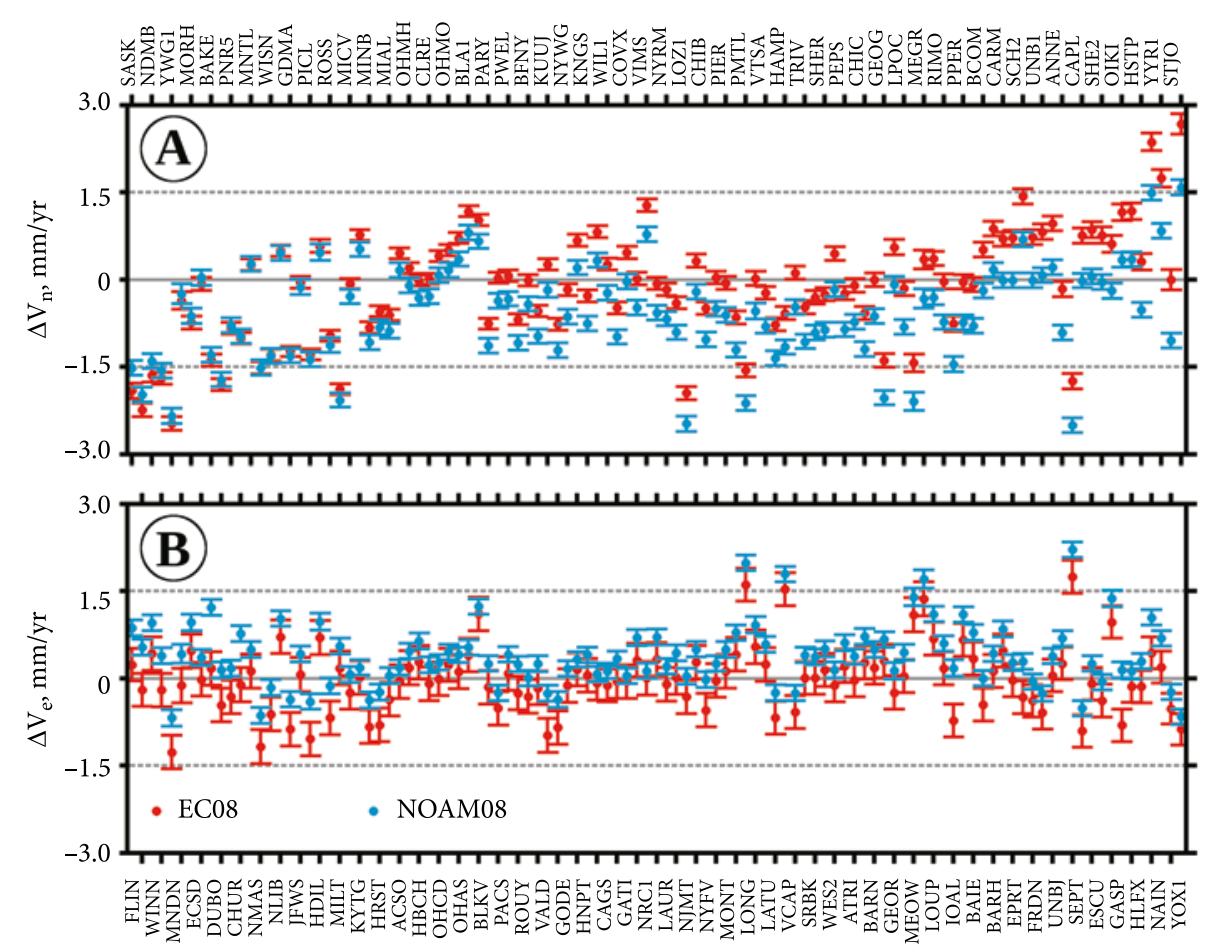

Fig. 5. (A) North and (B) east postfit residual velocities for all stations except MINW, HULL, GAS2, GODR, and MCHN. Stations are sorted according to their longitudes. In general, the postfit residual velocities calculated from eastern Canada ITRF 2008 (EC08) model are smaller especially for stations located at the Saint Lawrence River valley 
that show the GIA produces horizontal velocities of $1-2 \mathrm{~mm} / \mathrm{yr}$ in this region (Calais et al. 2006; George et al. 2011; Henton et al. 2006; Mazzotti, Adams 2005; Sella et al. 2007) and that it is difficult to discriminate this signal from smaller seismic strain.

We compared our results with the ICE-5G VM2 (Peltier 2004) and ICE-6G VM5a (Argus et al. 2014; Peltier et al. 2015). Both models provide vertical velocities and are publicly available at the Peltier's website (Peltier 2015). These models are composed of a history of ice thickness and extent that loads a specified rheological model of the earth (Sella et al. 2007). While the first model was mostly developed based on ice loading history and mantle viscosity structure, the latter model was refined mainly by vertical velocities obtained from GPS observations that constrain the thickness of the local ice cover as well as its removal time.

Vertical velocities of all stations estimated by Goudarzi et al. (2015a) are represented in Fig. 6A in order to compare them with the aforementioned GIA models. In general, GIA models are consistent with the horizontal and vertical CGPS-derived velocities to the first order. Figure $6 \mathrm{~B}$ shows the horizontal velocity field of the ICE-5G model over the study region. They are radially outward from the center of the thickest ice dome located to the west of Hudson Bay, gradually increasing at large distances, and then decreasing to zero. Beyond that, the velocity magnitude is increasing again but with an inversed direction radially inward to peripheral bulges. Comparing this figure with Fig. 4 reveals significant differences between the CGPS horizontal velocity field and the GIA model in direction and magnitude. Although not very homogeneous, the CGPS-derived velocity field clearly shows three ice load centers (as discussed before) over Canada, despite the only one ice dome in the GIA model. This discrepancy has also been observed by Sella et al. (2007) and Altamimi et al. (2012). Both GIA models predict uplift over the areas where heavy ice sheets had forced out portions of the mantle and subsidence around them as the mantle flows back, very similar to the CGPS vertical velocity field. The comparison, however, discovered a systematic difference between CGPS vertical velocities and GIA

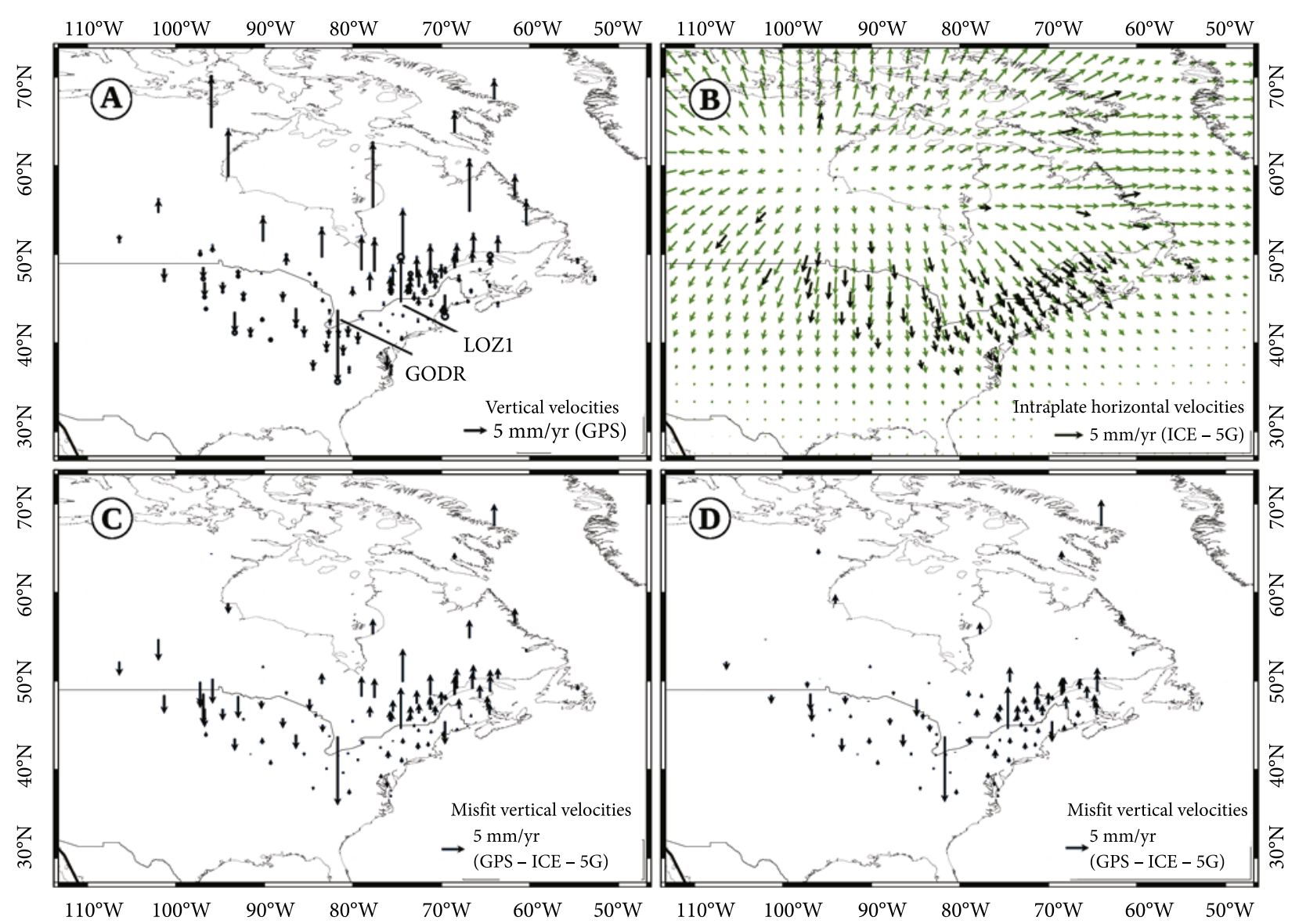

Fig. 6. (A) Overview of the vertical velocity field obtained from CGPS observations. Stations GODR and LOZ1 have very different vertical velocities with larger sigma values compared to the nearby stations and therefore are excluded. (B) Horizontal velocity field predicted by the ICE-5G model. Bold arrows show predicted velocities by this model at the CGPS stations.

(C-D) Misfits between CGPS-derived vertical velocities and predicted velocities from ICE-5G and ICE-6G models, respectively. Misfits in (C) are larger than in (D) and are spatially systematic. 
models, shown in Figure 6C and D, respectively. The misfit vertical velocities show an upward motion to the east and a downward motion to the west, indicating a major discrepancy between the assumed ice loading history and mantle viscosity structure, and the present-day GPS observations. The misfit vertical velocities are smaller in the ICE-6G model due mostly to the fact that this model has been refined by the vertical velocities of GPS observations (Argus et al. 2014; Peltier et al. 2015).

\section{Conclusions}

The interior part of the North American plate is subject to the GIA and intraplate tectonic activities. After its plate rotation, the ongoing GIA is by far the largest source of geophysical signal in eastern Canada. As this area is affected by the crustal deformation related to the GIA, many CGPS stations have a strong correlation to this process and the Euler pole is biased if they are included in the estimation. Therefore, selecting proper CGPS stations is crucial. Applying different constraints, a large number of CGPS stations in eastern Canada were reduced to 19 stations. Selected stations have an observation period of longer than three years with stable monuments and are far from GIA-affected regions, large earthquakes, and deformation zones. Moreover, they are spatially distributed in the eastwest direction along the hinge line and have a good geometrical coverage over the survey network.

We iteratively estimated the Euler pole using the selected CGPS stations. The small magnitudes of the residual velocities show that the retained stations in the final inversion are good representatives for estimating the Euler pole in the area. Furthermore, the intraplate horizontal velocities estimated by the EC08 model are generally smaller over the SLRV area that indicates our estimation is superior and can model the horizontal velocity field of this region better than the NOAM08 model.

The estimated parameters are different from those officially published for the whole North American plate. This indicates that the area is not rotating rigidly with the North American plate and has its own movement within the plate. The difference implies the accumulation of stress in the whole area in general and along the SLRV in particular. However, other reasons such as the different number, location, and the spatial distribution of CGPS stations for the NOAM08 estimation have less contribution to the difference.
The horizontal residual velocities, which present the intraplate velocity field after removing the whole rotation of the North American plate, show three centers of maximum uplift in eastern Canada that confirms the multidomed model of the LIS with two main centers over Labrador and Keewatin ice sheets and one other smaller dome shown as the Foxe ice cap. Furthermore, larger residual velocities on the west and north side of the SLRV compared to those on the opposite flank of the river indicate a continuous shortening along the valley. Comparing the vertical velocities of all stations with the ICE-5G and ICE-6G GIA models showed that they are generally consistent in either of horizontal or vertical directions to the first order. However, a systematic difference between our present-day CGPS vertical velocities and GIA models was observed. Similar discrepancy has also been reported by Kierulf et al. (2014) in northeastern Fennoscandia using the ICE-5G model. While they are attributed to the principal inconsistency between the assumed ice loading history and the mantle viscosity structure, and the present-day GPS observations, they point out the need for further detailed investigations in future.

\section{Acknowledgements}

This project has been partly funded by the grants of the Canadian NSERC and the Faculty of Forestry, Geography, and Geomatics (FFGG) of Laval University. We sincerely thank the anonymous reviewers for helping us to improve the quality of the paper by their comments. The following software programs were used as well as those mentioned in the text: MATLAB for numerical calculations, Quantum GIS software (QGIS 2015) for spatial analysis, and GIMP and Inkscape for creating figures.

\section{References}

Adams, J.; Basham, P. W. 1989a. Earthquakes at North-Atlantic passive margins: neotectonics and postglacial rebound, in S. Gregersen, P. W. Basham (Eds.). Earthquakes at North-atlantic passive margins: neotectonics and postglacial rebound, NATO ASI Series. Netherlands: Springer, 355-370.

Adams, J.; Basham, P. W. 1989b. The seismicity and seismotectonics of Canada east of the Cordillera, Geoscience Canada 16: 3-16.

Adams, J.; Basham, P. W. 1991. The seismicity and seismotectonics of eastern Canada, in D. B. Slemmons; E. R. Engdahl, M. D. Zoback, D. D. Blackwell (Eds.). Neotectonics of North America 1: 261-276.

http://dx.doi.org/10.1130/dnag-csms-neo.261

Altamimi, Z.; Collilieux, X.; Legrand, J.; Garayt, B.; Boucher, C. 2007. ITRF2005: A new release of the International Terrestrial Reference Frame based on time series of station 
positions and Earth Orientation Parameters, Journal of Geophysical Research: Solid Earth 112(B9).

http://dx.doi.org/10.1029/2007jb004949

Altamimi, Z.; Métivier, L.; Collilieux, X. 2012. ITRF2008 plate motion model, Journal of Geophysical Research: Solid Earth 117(B7). http://dx.doi.org/10.1029/2011jb008930

Altamimi, Z.; Sillard, P.; Boucher, C. 2002. ITRF2000: a new release of the International Terrestrial Reference Frame for earth science applications, Journal of Geophysical Research: Solid Earth 107(B10): 1-19.

http://dx.doi.org/10.1029/2001jb000561

Andrews, J. T. 1991. Late Quaternary glacial isostatic recovery of North America, Greenland, and Iceland: a neotectonics perspective, in D. B. Slemmons, E. R. Engdahl, M. D. Zoback, D. D. Blackwell (Eds.). Neotectonics of North America 1: 473-486. http://dx.doi.org/10.1130/dnag-csms-neo.473

Argus, D. F.; Gordon, R. G. 1991. No-net-rotation model of current plate velocities incorporating plate motion model NUVEL-1, Geophysical Research Letters 18(11): 2039-2042. http://dx.doi.org/10.1029/91gl01532

Argus, D. F.; Gordon, R. G. 1996. Tests of the rigid-plate hypothesis and bounds on intraplate deformation using geodetic data from very long baseline interferometry, Journal of Geophysical Research 101(B6): 13555-13572.

http://dx.doi.org/10.1029/95jb03775

Argus, D. F.; Gordon, R. G.; Heflin, M. B.; Ma, C.; Eanes, R. J.; Willis, P.; Peltier, W. R.; Owen, S. E. 2010. The angular velocities of the plates and the velocity of Earth's centre from space geodesy, Geophysical Journal International 180(3): 913-960. http://dx.doi.org/10.1111/j.1365-246x.2009.04463.x

Argus, D. F.; Heflin, M. B. 1995. Plate motion and crustal deformation estimated with geodetic data from the Global Positioning System, Geophysical Research Letters 22(15): 1973-1976. http://dx.doi.org/10.1029/95gl02006

Argus, D. F.; Peltier, W. R. 2010. Constraining models of postglacial rebound using space geodesy: A detailed assessment of model ICE-5G (VM2) and its relatives, Geophysical Journal International 181: 697-723.

http://dx.doi.org/10.1111/j.1365-246x.2010.04562.x

Argus, D. F.; Peltier, W. R.; Drummond, R.; Moore, A. W. 2014. The Antarctica component of postglacial rebound model ICE-6G_C (VM5a) based on GPS positioning, exposure age dating of ice thicknesses, and relative sea level histories, Geophysical Journal International 198(1): 537-563.

http://dx.doi.org/10.1093/gji/ggu140

Bird, P. 2003. An updated digital model of plate boundaries, Geochemistry, Geophysics, Geosystems 4(3): 1027. http://dx.doi.org/10.1029/2001gc000252

Blewitt, G.; Lavallée, D. 2002. Effect of annual signals on geodetic velocity, Journal of Geophysical Research 107(B7): 2145. http://dx.doi.org/10.1029/2002jb002297

Braun, A.; Kuo, C. Y.; Shum, C. K.; Wu, P.; van der Wal, W.; Fotopoulos, G. 2008. Glacial isostatic adjustment at the Laurentide ice sheet margin: Models and observations in the Great Lakes region, Journal of Geodynamics 46(3-5): 165-173.

Calais, E.; Han, J. Y.; DeMets, C.; Nocquet, J. M. 2006. Deformation of the North American plate interior from a decade of continuous GPS measurements, Journal of Geophysical Research 111: B06402. http://dx.doi.org/10.1029/2005jb004253

Chase, C. G. 1972. The N plate problem of plate tectonics, Geophysical Journal of the Royal Astronomical Society 29(2): 117-122. http://dx.doi.org/10.1111/j.1365-246X.1972.tb02202.x
Dach, R.; Hugentobler, U.; Fridez, P.; Meindl, M. 2007. The Bernese GPS software version 5.0. Astronomical Institute, University of Bern, Bern, Switzerland.

DeMets, C.; Gordon, R. G.; Argus, D. F. 2010. Geologically current plate motions, Geophysical Journal International 181(1): 1-80. http://dx.doi.org/10.1111/j.1365-246x.2009.04491.x

DeMets, C.; Gordon, R. G.; Argus, D. F.; Stein, S. 1990. Current plate motions, Geophysical Journal International 101(2): 425-478.

http://dx.doi.org/10.1111/j.1365-246x.1990.tb06579.x

Dow, J. M.; Neilan, R. E.; Rizos, C. 2009. The International GNSS Service in a changing landscape of Global Navigation Satellite Systems, Journal of Geodesy 83(3-4): 191-198. http://dx.doi.org/10.1007/s00190-008-0300-3

George, N. V.; Tiampo, K. F.; Sahu, S. S.; Mazzotti, S.; Mansinha, L.; Panda, G. 2011. Identification of glacial isostatic adjustment in Eastern Canada using $S$ transform filtering of GPS observations, Pure and Applied Geophysics 169(8): 1507-1517. http://dx.doi.org/10.1007/s00024-011-0404-1

Ghilani, C. D. 2010. Adjustment computations: spatial data anal$y$ sis. $5^{\text {th }}$ ed. Hoboken: John Wiley \& Sons. http://dx.doi.org/10.1002/9780470586266

Goudarzi, M. A.; Cocard, M.; Santerre, R. 2015a. Present-day velocity field of eastern North America based on continuous GPS observations (unpublished manuscript).

Goudarzi, M. A.; Cocard, M.; Santerre, R. 2015b. Noise behavior in CGPS position time series: the eastern North America case study, Journal of Geodetic Science 5(1): 119-147. http://dx.doi.org/10.1515/jogs-2015-0013

Goudarzi, M. A.; Cocard, M.; Santerre, R. 2013a. EPC: Matlab software to estimate Euler pole parameters, GPS Solutions 18(1): 153-162. http://dx.doi.org/10.1007/s10291-013-0354-4

Goudarzi, M. A.; Cocard, M.; Santerre, R.; Woldai, T. 2013b. GPS interactive time series analysis software, GPS Solutions 17(4): 595-603. http://dx.doi.org/10.1007/s10291-012-0296-2

Henton, J. A.; Craymer, M. R.; Ferland, R.; Dragert, H.; Mazzotti, S.; Forbes, D. L. 2006. Crustal motion and deformation monitoring of the Canadian landmass, Geomatica 60: 173-191.

Kierulf, H. P.; Ouassou, M.; Simpson, M. J. R.; Vestøl, O. 2013. A continuous velocity field for Norway, Journal of Geodesy 87(4): 337-349. http://dx.doi.org/10.1007/s00190-012-0603-2

Kierulf, H. P.; Steffen, H.; Simpson, M. J. R.; Lidberg, M.; Wu, P.; Wang, H. 2014. A GPS velocity field for Fennoscandia and a consistent comparison to glacial isostatic adjustment models, Journal of Geophysical Research: Solid Earth 119(8): 6613-6629. http://dx.doi.org/10.1002/2013jb010889

Kreemer, C.; Blewitt, G.; Klein, E. C. 2014. A geodetic plate motion and Global Strain Rate Model, Geochemistry, Geophysics, Geosystems 15(10): 3849-3889.

http://dx.doi.org/10.1002/2014gc005407

Kreemer, C.; Holt, W. E. 2001. A no-net-rotation model of present-day surface motions, Geophysical Research Letters 28(23): 4407-4410. http://dx.doi.org/10.1029/2001gl013232

Kreemer, C.; Lavallée, D. A.; Blewitt, G.; Holt, W. E. 2006. On the stability of a geodetic no-net-rotation frame and its implication for the International Terrestrial Reference Frame, Geophysical Research Letters 33(17). http://dx.doi.org/10.1029/2006gl027058

Lambert, A.; Courtier, N.; Sasagawa, G.; Klopping, F.; Winester, D.; James, T. S.; Liard, J. O. 2001. New constraints on 
Laurentide postglacial rebound from absolute gravity measurements, Geophysical Research Letters 28(10): 2109-2112. http://dx.doi.org/10.1029/2000gl012611

Lamontagne, M. 2008. Casualties directly caused by an earthquake in Canada: First contemporaneous written accounts from the M 6.5 Charlevoix, Quebec, earthquake of 20 October 1870, Bulletin of the Seismological Society of America 98(3): 1602-1606. http://dx.doi.org/10.1785/0120070227

Langbein, J.; Johnson, H. 1997. Correlated errors in geodetic time series: implications for time-dependent deformation, Journal of Geophysical Research: Solid Earth 102(B1): 591603. http://dx.doi.org/10.1029/96jb02945

Lavoie, C.; Allard, M.; Duhamel, D. 2012. Deglaciation landforms and C-14 chronology of the Lac Guillaume-Delisle area, eastern Hudson Bay: a report on field evidence, Geomorphology 159-160: 142-155. http://dx.doi.org/10.1016/j.geomorph.2012.03.015

Lowrie, W. 2007. Fundamentals of geophysics. $2^{\text {nd }}$ ed. New York: Cambridge University Press. http://dx.doi.org/10.1017/cbo9780511807107

Mazzotti, S.; Adams, J. 2005. Rates and uncertainties on seismic moment and deformation in eastern Canada, Journal of Geophysical Research 110(B9).

http://dx.doi.org/10.1029/2004jb003510

Mazzotti, S.; James, T. S.; Henton, J. A.; Adams, J. 2005. GPS crustal strain, postglacial rebound, and seismic hazard in eastern North America: The Saint Lawrence valley example, Journal of Geophysical Research 110(B11). http://dx.doi.org/10.1029/2004jb003590

Minster, J. B.; Jordan, T. H. 1978. Present-day plate motions, Journal of Geophysical Research 83(B11): 5331-5354. http://dx.doi.org/10.1029/jb083ib11p05331

Natural Resources Canada (NRCan). 2015. Earthquakes Canada [online], [cited 3 April 2015]. Available from Internet: http://www.earthquakescanada.nrcan.gc.ca/index-eng.php

Natural Resources Canada (NRCan). 2013. Earthquake zones in Eastern Canada [online], [cited 3 February 2015]. Available from Internet: http://earthquakescanada.nrcan.gc.ca/zones/ eastcan-eng.php

Park, K. D.; Nerem, R. S.; Davis, J. L.; Schenewerk, M. S.; Milne, G. A.; Mitrovica, J. X. 2002. Investigation of glacial isostatic adjustment in the northeast US using GPS measurements, Geophysical Research Letters 29(11): 1509. http://dx.doi.org/10.1029/2001gl013782

Peltier, W. R. 2015. Paleo topography data [online], [cited 05 June 2015]. Available from Internet: http://www.atmosp. physics.utoronto.ca/ peltier/data.php

Peltier, W. R. 2004. Global glacial isostasy and the surface of the Ice-Age Earth: The ICE-5G (VM2) Model and GRACE, $A n-$ nual Review of Earth and Plannetary Sciences 32(1): 111-149. http://dx.doi.org/10.1146/annurev.earth.32.082503.144359

Peltier, W. R.; Argus, D. F.; Drummond, R. 2015. Space geodesy constrains Ice Age terminal deglaciation: The global ICE6G_C (VM5a) model, Journal of Geophysical Research: Solid Earth 120: 450-487. http://dx.doi.org/10.1002/2014jb011176

Pope, A. J. 1976. The statistics of residuals and the detection of outliers. NOAA Technical Report NOS 65, NGS 1. Rockville: National Ocean Survey.
QGIS. 2015. QGIS: A Free and Open Source Geographic Information System [online], [cited 02 June 2015]. Available from Internet: http://qgis.osgeo.org

Schotman, H. H. A.; Vermeersen, L. L. A. 2005. Sensitivity of glacial isostatic adjustment models with shallow low-viscosity earth layers to the ice-load history in relation to the performance of GOCE and GRACE, Earth and Planetary Science Letters 236(3-4): 828-844. http://dx.doi.org/10.1016/j.epsl.2005.04.008

Sella, G. F.; Dixon, T. H.; Mao, A. 2002. REVEL: a model for recent plate velocities from space geodesy, Journal of Geophysical Research 107(B4): 2081. http://dx.doi.org/10.1029/2000jb000033

Sella, G. F.; Stein, S.; Dixon, T. H.; Craymer, M. R.; James, T. S.; Mazzotti, S.; Dokka, R. K. 2007. Observation of glacial isostatic adjustment in "stable" North America with GPS, Geophysical Research Letters 34(2): 2306. http://dx.doi.org/10.1029/2006gl027081

Sella, G. F.; Stein, S.; Wdowinski, S.; Dixon, T. H.; Craymer, M. R.; James, T. S. 2004. Direct constraints on GIA motion in North America using GPS, in AGU Spring Meeting Abstracts. P. 3.

Törnqvist, T. E.; Hijma, M. P. 2012. Links between early Holocene ice-sheet decay, sea-level rise and abrupt climate change, Nature Geoscience 5(9): 601-606. http://dx.doi.org/10.1038/ngeo1536

van der Wal, W.; Braun, A.; Wu, P.; Sideris, M. G. 2009. Prediction of decadal slope changes in Canada by glacial isostatic adjustment modelling, Canadian Journal of Earth Sciences 46(8): 587-595. http://dx.doi.org/10.1139/e09-044

Mohammad Ali GOUDARZI, PhD candidate in Geodesy at Laval University, Canada. Since 2001, his job and research activities have been focused on earth surface deformation studies using GPS observations and SAR interferometry. His research interests include GPS time series and crustal strain analysis, among others. He is currently studying the geodetic crustal deformation of eastern Canada using continuous GPS observations.

Marc COCARD is a professor of Geodesy at the Department of Geomatics Sciences of Laval University, and a regular member of the Centre for Research in Geomatics. His research interests relate to the efficient exploitation and future applications of GNSS including, among others, mitigation of the different error sources.

Rock SANTERRE is a full professor of Geodesy and GPS in the Department of Geomatics Sciences and a member of the Centre for Research in Geomatics at Laval University. Since 1983, his research activities have been mainly related to high precision GPS for static and kinematic positioning. Dr Santerre is the author and co-author of more than 150 publications and he holds three patents related to GPS equipment. 